\title{
RETROESPECTIVA HISTÓRICA DO ENSINO JURÍDICO NO BRASIL DURANTE A REPÚBLICA VELHA
}

\section{HISTORICAL RETROSPECTIVE OF LEGAL EDUCATION IN BRAZIL DURING THE OLD REPUBLIC}

\author{
${ }^{1}$ Thais Seravali Munhoz Arroyo Busiquia \\ ${ }^{2}$ Larissa Yukie Couto Munekata
}

\section{RESUMO}

O ensino jurídico no Brasil no período da República Velha mostrou-se conturbado por ter havido inúmeras reformas, o que gerou insegurança e instabilidade ao estudante dessa época. Para entender os motivos dessa afirmação, mostra-se relevante traçar a evolução histórica do ensino jurídico no Brasil do mencionado período, enfatizando eventuais problemas, pontos positivos e diferenças em relação a outros períodos. Dentre as citadas, há uma menção mais detalhada com relação à: Reforma Benjamin Constant, Rivadávia Corrêa e a Carlos Maximiliano. Destaca-se que os cursos jurídicos no Brasil nessa primeira fase da República foram precursores dos atuais lecionados nas instituições de ensino superior público e privado do país. Por fim, apresentar-se-á a metodologia de ensino, filosofia, o perfil do profissional do direito e as principais figuras jurídicas relacionadas ao período em destaque.

Palavras-chave: Ensino jurídico, República velha, Evolução

\begin{abstract}
The legal education in Brazil's Old Republic period was disturbed by several reforms, which caused insecurity and instability feelings on contemporary students. To understand the reasons underlying the statement above, its relevant to trace the historical evolution of Brazil's legal education in that period, emphasizing possible problems, strengths and differences from other periods. Among the aforementioned, there is a more detailed approach regarding these legal education reforms: Benjamin Constant, Rivadavia Correa and Carlos Maximiliano. It is noteworthy that the legal courses in Brazil's first-phase Republic were precursors of nowadays taught courses in public and private higher education institutions in the country. Finally, it will present the teaching methodology, philosophy, the law professional profile and the main legal figures related to the featured period.
\end{abstract}

Keywords: Legal education, Old republic, Evolution

\footnotetext{
${ }^{1}$ Mestranda em Direitos da Personalidade na Centro Universitário de Maringá - CEUMAR, Paraná (Brasil). E-mail: thaiseravali@ hotmail.com

${ }^{2}$ Mestranda em Ciências Jurídicas no Centro de Ensino Superior de Maringá - CESUMAR, Paraná (Brasil).

E-mail: larissa.munekata@ hotmail.com
} 


\section{INTRODUÇÃO}

Antes de iniciarmos o estudo acerca da evolução, problemas e diferenças do ensino jurídico no período da primeira República do país (instalada em 15 de novembro de 1889 com a queda da monarquia pelo golpe militar), deve-se considerar primeiramente o fato (de certo modo ainda atrelado a nossa cultura) de que o Brasil foi fortemente influenciado pelos preceitos e doutrinas trazidas pelo Direito de Portugal que, como país colonizador, desde a época do descobrimento colaborou (e por outro lado atrasou) com a cultura social brasileira.

Dotado de sérios problemas desde os seus primórdios, o ensino jurídico tem sido estudado por vários autores brasileiros que têm dirigido várias críticas com relação ao currículo, metodologia e até o próprio tipo de conhecimento que é ensinado em sala de aula.

O objetivo geral do presente artigo é enfatizar a evolução histórica do ensino jurídico no Brasil no período da República Velha, trazendo as alterações legislativas realizadas. Os objetivos específicos consistem em analisar o currículo, a metodologia de ensino, a filosofia, o perfil exigido do aluno, bem como eventuais problemas, diferenças e pontos positivos, principalmente do mencionado período com o Imperial carregado das influências portuguesas.

Como justificativa, cita-se a relevância da abordagem do tema pela necessidade de compreensão da evolução histórica do ensino do Direito para que se possa compreender os problemas atuais enfrentados nas faculdades e universidades nessa área.

Como método de abordagem irá se utilizar do indutivo, pois o assunto é abordado de forma particular, porém com aspectos abrangentes, caminhando para muitas discussões. Quanto ao método de procedimento, utilizar-se-á o comparativo, pois haverá a comparação entre o período Imperial e República, no tocante às divergências. O método de investigação será o bibliográfico, pois o uso de obras e artigos científicos será a base de pesquisa.

\section{AS REFORMAS NO ENSINO JURÍDICO DA REPÚBLICA VELHA}

Percebe-se no decorrer do período que o ensino jurídico passou por várias reformas e mudanças na grade curricular do curso, gerando instabilidade. Porém Antônio A. Machado diz que a estrutura curricular dos cursos jurídicos no século XIX e nas primeiras décadas do século XX possuía um "[...] perfil equilibrado entre as disciplinas técnicas, ou dogmáticas e aquelas de conteúdo mais político ou filosófico"”.

\footnotetext{
1 MACHADO, Antônio Alberto. Ensino jurídico e mudança social. 2. ed. São Paulo: Expressão Popular, 2009 , p. 98.
} 
Enfatiza-se que inicialmente a oportunidade de acesso ao mesmo era apenas para quem havia alto poder econômico. Porém, ainda assim era indispensável sua criação, tendo em vista o Brasil necessitar de crescimento e fortalecimento educacional.

Flávio Antonio E. Galdino² afirma que no período da República Velha a formação jurídica era descompromissada com a realidade social e com a transformação do país, bem como era ineficiente.

Como bem destacou José Sebastião de Oliveira [et. al] ${ }^{3}$, no período de 100 anos compreendido do Império até a República Velha houve mais de 25 normas na tentativa de regulamentação do ensino jurídico no Brasil, comprovando portanto a insegurança vivenciada pelos alunos (porém a abrangência do presente trabalho será dada a apenas 11 normas). Ainda, estabelece a seguinte crítica:

\begin{abstract}
É nessa efervescência legislativa, vivida até hoje no Brasil que os cursos de direito de (sic) desenvolveram, muitas vezes voltados não apenas à intenção de criar a elite intelectual do país, mas satisfazer aos interesses e as aspirações pessoais do governo, do deputado, do jurista, daqueles que, enfim, detinham a possibilidade de mudança. [...] o ensino jurídico ainda sofria de uma séria parcialidade: era desprovido do espírito livre e exigia, ao menos na letra fria, que o lente seguisse determinados compêndios e não adotasse doutrinas e entendimentos considerados revolucionários à época. [...] $\mathrm{O}$ dirigismo estatal buscava - e nesse ponto foi altamente eficiente - a formação da classe dominante do poder ${ }^{4}$.
\end{abstract}

A crítica é construtiva e autoexplicativa no sentido de entender o motivo do ensino jurídico ter sido carente e impossibilitado de crescer como deveria. O fato de ser muito caro e de difícil acesso dificultava a possibilidade de adquirir cultura e uma profissão nesta área. Além do mais, por preponderar o positivismo e o liberalismo, impossibilitava a construção crítica, filosófica e real dos problemas que a sociedade enfrentava na época.

Um dado relevante apresentado por José Sebastião de Oliveira [et. al] é que até o fim da monarquia não foi implantado sequer 1 universidade no Brasil. Holmes Cordeiro Neto

\footnotetext{
2 GALDINO, Flávio Antonio Esteves. A Ordem dos Advogados do Brasil na reforma do ensino jurídico. In: Ensino Jurídico OAB: 170 anos de cursos jurídicos no Brasil. Brasília: OAB, Conselho Federal, 1997, p. 159-160.

3 OLIVEIRA, José Sebastião de; TOFFOLI, Vitor. O ensino jurídico em nosso país no período imperial e no primeiro momento republicano, sua evolução histórico-metodológica e suas consequências na contemporaneidade. Sistema Jurídico e Direitos fundamentais individuais e Coletivos. 1. ed. Florianópolis: Fundação Bouitex, 2012, p. 8660, 8669.

4 OLIVEIRA, José Sebastião de; TOFFOLI, Vitor. Op. cit., p. 8662.

5 OLIVEIRA, José Sebastião de; TOFFOLI, Vitor. Op. cit., p. 8669.
} 
[et. al] ${ }^{6}$ complementa que em 1889 havia 19 cursos de ensino superior no Brasil. A seguir passar-se-á a análise específica destas reformas.

\subsection{Decreto no 10.361 , de 14 de novembro de 1890}

Este decreto, de acordo com Aurélio Wander Bastos ${ }^{7}$, foi assinado por Marechal Deodoro da Fonseca e pelo Ministro de Instrução Benjamin Constant, retirando a cadeira de Direito Eclesiástico do currículo dos cursos jurídicos das cidades de Recife e São Paulo, separando definitivamente a Igreja do Estado.

\subsection{Decreto ${ }^{\circ}$ 1.232H de 2 de janeiro de 1891: Reforma Benjamin Constant}

Este decreto também é conhecido por Reforma Benjamin Constant, pois foi assinado por Benjamin Constant Botelho de Magalhães ${ }^{8}$. De acordo com Aurélio Wander Bastos, esta reforma dizia respeito às Instituições de Ensino Jurídico dependentes do Ministério da Instrução Pública; bem como "incentivava modelos de descentralização escolar, onde o ensino livre, enriquecido, teve papel fundamental ${ }^{9}$ ". Em outras palavras, o ensino não estava mais centralizando apenas em Recife e São Paulo.

Este decreto em seu artigo $217^{10}$, permitiu a abertura de cursos livres nas Faculdades Federais para quem tivesse a aprovação pelas mesmas, ou outras equivalentes nacionais ou estrangeiras, nas matérias que pretendessem lecionar, desde que tivesse toda a documentação necessária. Mas mesmo assim, no artigo $220^{11}$ apresenta que os cursos livres deveriam ser inspecionados pelo Diretor, pois não poderia apresentar doutrinas contrárias à lei moral, gerar desordem ou desprezar os programas, podendo haver suspensão da licença do curso livre.

\footnotetext{
6 CORDEIRO NETO, Holmes; AMORIM, Rosendo Freitas de. O ensino superior na primeira república no Brasil e a pedagogia de Ruy Barbosa. In: XXIII Congresso Nacional do CONPEDI, 2014, João Pessoa. Direito, ensino e metodologia jurídicos II. XXIII Congresso Nacional do CONPEDI. Florianópolis: CONPEDI, 2014, p. 525 .

7 BASTOS, Aurélio Wander. O ensino jurídico no Brasil. 2. ed. Rio de Janeiro: Lumen Juris, 2000, p. 153.

8 BRASIL. Decreto n. 1.232-H, de 2 de janeiro de 1891, que aprova o regulamento das Instituições de Ensino Jurídico, dependentes do Ministério da Instrução Pública. In: Decretos do Governo Provisorio da Republica dos Estados Unidos do Brazil. Primeiro fascículo de 1 a 31 de janeiro de 1891. Rio de Janeiro: Imprensa Nacional, $1891 . \quad$ Disponível em: <http://www.camara.gov.br/Internet/InfDoc/novoconteudo/Legislacao/Republica/LeisOcerizadas/1891dgp-jan.pdf>, p. 5. Acesso em 16 jun. 2015 .

9 BASTOS, Aurélio Wander. Op. cit., p. 152.

10 BRASIL. Decreto n. 1.232-H, de 2 de janeiro de 1891. Op. cit., p. 34. Acesso em 16 jun. 2015.

11 BRASIL. Decreto n. 1.232-H, de 2 de janeiro de 1891. Op. cit., p. 34. Acesso em 16 jun. 2015.
} 
Alberto Venancio Filho ${ }^{12}$ afirma que poderia haver a abertura de cursos ou de estabelecimentos por particulares ou associação de particulares, desde que se ensinasse as mesmas matérias de curso ou de faculdade federal e fossem inspecionadas pelo Conselho de Instrução Superior; e se esse estabelecimento fosse satisfatório poderia adquirir pelo Governo e o Conselho de Instrução Superior o título de faculdade livre, com os mesmos benefícios e garantias das faculdades federais.

Após essa regra a Faculdade Livre de Direito da Bahia (instalada em 15 de abril de 1891) foi a primeira autorizada a funcionar ${ }^{13}$. Ainda, estipulou-se ${ }^{14}$ que em cada uma das Faculdades de Direito deveria haver 3 cursos diversos e com finalidades diferentes: a) de ciências jurídicas (em 4 séries); b) de ciências sociais (em 3 séries) e, c) de notariado (em 2 séries).

Nas Faculdades de Direito as matérias do curso de Ciências Jurídicas seriam ${ }^{15}$ : a) $1^{\text {a }}$ série: Filosofia e História do Direito ( $1^{\mathrm{a}}$ cadeira) e Direito público e constitucional (2a cadeira); b) $2^{\mathrm{a}}$ série: Direito romano ( $1^{\mathrm{a}}$ cadeira), Direito civil ( $2^{\mathrm{a}}$ cadeira), Direito comercial ( 3 cadeira) e Direito criminal ( $4^{\mathrm{a}}$ cadeira); c) $3^{\mathrm{a}}$ série: Medicina legal ( $1^{\mathrm{a}}$ cadeira), Direito civil - continuação da $2^{\mathrm{a}}$ cadeira da $2^{\mathrm{a}}$ série $\left(2^{\mathrm{a}}\right.$ cadeira) e Direito comercial - continuação da $3^{\mathrm{a}}$ cadeira da $2^{\mathrm{a}}$ série ( $3^{\mathrm{a}}$ cadeira); d) $4^{\mathrm{a}}$ série: História do Direito nacional ( $1^{\mathrm{a}}$ cadeira), Processo criminal, civil e comercial ( $2^{\mathrm{a}}$ cadeira), Economia política e Direito administrativo ( $3^{\mathrm{a}}$ cadeira), Prática forense ( $4^{\mathrm{a}}$ cadeira).

Neste período da Reforma Benjamin Constant: a) trocou-se o ensino do Direito Natural para a Filosofia do Direito, História do Direito e História do Direito Nacional, que fora influenciado pela proposta de Rui Barbosa (que não foi aprovada durante o período Imperial) e; b) não se estimulava o estudo de Direito Processual, mesmo porque havia a descentralização estadual do processo, conforme a Constituição de $1891^{16}$.

Alberto Venancio Filho ${ }^{17}$ afirma que este decreto também determinava que: a) o professor faria a explicação da matéria ou a correção da doutrina errônea ou menos correta, sendo que caso os alunos tivessem dúvidas, deveriam ser expostas verbalmente ou por escrito,

\footnotetext{
12 VENANCIO FILHO, Alberto. Das Arcadas ao Bacharelismo: 150 anos de Ensino Jurídico no Brasil. São Paulo: Perspectiva, 1982, p. 183.

13 VENANCIO FILHO, Alberto. Das Arcadas ao Bacharelismo: 150 anos de Ensino Jurídico no Brasil. São Paulo: Perspectiva, 1982, p. 186.

${ }^{14}$ BRASIL. Decreto $n$. 1.232-H, de 2 de janeiro de 1891. Op. cit., p. 5. Acesso em 16 jun. 2015.

${ }^{15}$ BRASIL. Decreto n. 1.232-H, de 2 de janeiro de 1891. Op. cit., p. 6. Acesso em 16 jun. 2015.

${ }^{16}$ BASTOS, Aurélio Wander. Op. cit., p. 155-156.
} 
podendo o lente resolver na próxima aula ou até no mesmo dia e; b) as aulas na faculdade começariam em $1^{\circ}$ de abril e finalizariam em 14 de novembro.

$\mathrm{O}$ artigo $418^{18}$ também permite que os poderes dos estados federativos criem faculdades de Direito, porém devem seguir as mesmas regras para habilitação de matrículas e exames das Faculdades Federais, bem como devem ser inspecionadas pelo Conselho de Instrução Superior. Ficava assim definida a "[...] tríade de ação do ensino jurídico superior no Brasil: ensino oficial, ensino particular e ensino estadual ${ }^{19}$ ".

Porém um mês após a reforma, o sucessor de Benjamin Constant ${ }^{20}$ decretou medidas parciais que mudou completamente o sentido do plano geral de ensino, tais como a expedição de vários regulamentos com relação ao pessoal docente, às gratificações, prêmios, entre outros. Portanto, deveria haver uma nova reforma.

\subsection{Decreto $\mathrm{n}^{\circ}$ 639, de 31 de outubro de 1891}

O presente decreto foi assinado por Antônio Luís Affonso de Carvalho, em que se concedeu $^{21}$ à Faculdade Livre de Ciências Jurídicas e Sociais do Rio de Janeiro e à Faculdade Livre de Direito desta Capital o título de Faculdades Livres, com os privilégios e garantias das Faculdades Federais.

\subsection{Decreto $\mathrm{n}^{\circ}$ 1.159, de 3 de dezembro de 1892}

Foi assinado por Floriano Peixoto e Fernando Lobo, estabelecendo que duas faculdades de Direito serão mantidas pelo governo, sendo uma em São Paulo e outra em Pernambuco ${ }^{22}$.

\subsection{Lei $n^{\circ} 314$, de 30 de outubro de 1895}

Esta $1 \mathrm{ei}^{23}$ determinou o fechamento do curso de Ciências Sociais e de Notariado, devendo aquele funcionar por mais dois anos, e este por apenas mais um ano.

\footnotetext{
${ }^{18}$ BRASIL. Decreto n. 1.232-H, de 2 de janeiro de 1891. Op. cit., p. 55. Acesso em 16 jun. 2015.

${ }^{19}$ BASTOS, Aurélio Wander. Op. cit., p. 154.

${ }^{20}$ VENANCIO FILHO, Alberto. Das Arcadas ao Bacharelismo: 150 anos de Ensino Jurídico no Brasil. São Paulo: Perspectiva, 1982, p. 190.

${ }^{21}$ OLIVEIRA, José Sebastião de; TOFFOLI, Vitor. Op. cit., p. 8662.
} 
Houve a reorganização do ensino das faculdades de Direito através desta Lei, sendo importante apontar os seguintes fatores: a) consolidou-se em um único curso, nascendo desta forma o curso de Ciências Jurídicas e Sociais; b) deu autonomia à disciplina de Filosofia do Direito, História do Direito e Economia política e; c) introduziu a disciplina de Direito Internacional Público, Teoria do Processo Civil, Comercial e Criminal, Direito Administrativo e Ciência da Administração, Legislação Comparada sobre Direito Privado, Ciência das Finanças e Contabilidade do Estado ${ }^{24}$.

Esta lei $^{25}$ determinou que as faculdades de Direito deverão seguir o ensino em 5 anos, tendo as seguintes matérias: a) $1^{\mathrm{a}}$ ano: Filosofia do Direito ( $1^{\mathrm{a}}$ cadeira), Direito romano ( $2^{\mathrm{a}}$ cadeira), Direito público e constitucional ( $3^{\mathrm{a}}$ cadeira); b) $2^{\mathrm{o}}$ ano: Direito civil ( $1^{\mathrm{a}}$ cadeira), Direito criminal ( $1^{\mathrm{a}}$ cadeira), Direito internacional público e diplomacia ( $3^{\mathrm{a}}$ cadeira) e Economia política ( $4^{\mathrm{a}}$ cadeira); c) $3^{\mathrm{o}}$ ano: Direito comercial ( $1^{\mathrm{a}}$ cadeira), Direito Civil (2 $2^{\mathrm{a}}$ cadeira), Direito criminal, especialmente Direito militar e regime penitenciário ( $2^{\mathrm{a}}$ cadeira), Ciência das finanças e contabilidade do Estado (continuação da $4^{\mathrm{a}}$ cadeira do $2^{\circ}$ ano $-3^{\mathrm{a}}$ cadeira); d) $4^{\circ}$ ano: Direito comercial, especialmente Direito marítimo, falência e liquidação judicial ( $2^{\mathrm{a}}$ cadeira), Direito civil ( $3^{\mathrm{a}}$ cadeira), Teoria do processo civil, comercial e criminal ( $3^{\mathrm{a}}$ cadeira $)$ e Medicina pública ( $4^{\mathrm{a}}$ cadeira); e) $5^{\circ}$ ano: Prática forense (continuação da $3^{\mathrm{a}}$ cadeira do $4^{\mathrm{o}}$ ano $-1^{\mathrm{a}}$ cadeira), Ciência da administração e Direito administrativo ( $2^{\mathrm{a}}$ cadeira), História do Direito e especialmente do Direito nacional ( $3^{\mathrm{a}}$ cadeira) e Legislação comparada sobre o Direito privado ( $4^{\mathrm{a}}$ cadeira).

Esta lei $^{26}$ foi importante para novas reformas, pois restabeleceu a frequência em um livro especial que ficaria aos cuidados do professor, sendo que no final de cada mês eram extraídas as notas para o reconhecimento do número de faltas dadas pelos alunos, afixando-se em formato de edital na instalação da faculdade para que pudessem ser realizadas as reclamações (se necessárias); e melhorou o aproveitamento dos alunos e as condições de ensino e; c) diante da mudança do período fundou-se em 17 de fevereiro de 1900 outra faculdade livre, qual seja a Faculdade de Direito de Porto Alegre.

\footnotetext{
${ }^{23}$ BRASIL. Lei $n^{\circ}$ 314, de 30 de outubro de 1895, que reorganiza o ensino das Faculdades de Direito. Disponível em: <http://www2.camara.leg.br/legin/fed/lei/1824-1899/lei-314-30-outubro-1895-540752-publicacaooriginal 41651-pl.html $>$. Acesso em 23 jul. 2015.

${ }^{24}$ BASTOS, Aurélio Wander. Op. cit., p. 157, 164.

${ }^{25}$ BRASIL. Lei $n^{\circ}$ 314, de 30 de outubro de 1895. Op. cit. Acesso em 23 jul. 2015.
}

Revista de Pesquisa e Educação Jurídica | e-ISSN: 2525-9636 | Minas Gerais | v. 1 | n. 2 | p. 213 - 239 | Jul/Dez. 2015. 
Inclusive o artigo $5^{\circ}$ estabeleceu ${ }^{27}$ novas regras, sendo que para que as Faculdades Livres fossem reconhecidas e pudessem desfrutar de regalias e vantagens, deveriam ter patrimônio de 50.000 \$ (com prazo máximo de 5 anos para sua constituição), representadas por apólices da dívida pública geral ou pelo edifício em que as mesmas funcionavam; por 2 anos a frequência nunca devia ser inferior a 30 alunos; e observar o regime de ensino prescrito na lei.

Por mais que o nome seja "Faculdade Livre", de acordo com o artigo $7^{\circ}$ o governo nomeava um fiscal com competência científica no ensino jurídico, que realizava relatórios semestrais de cada faculdade sobre o programa e merecimento do ensino, marcha do processo dos exames, natureza das provas exibidas, condições de admissão à matricula e o regime do ensino adotado.

De acordo com o artigo $2^{\circ}$, as aulas iniciavam no dia 15 de março, finalizando no dia 15 de novembro. Com relação à matrícula, o artigo $8^{\circ}$ explica que devia preencher as condições da lei. Caso contrário, o fiscal ou qualquer cidadão deveriam denunciar em formato de inquérito, podendo acarretar a suspensão da faculdade de 1 a 2 anos. Ainda, se ocorresse abuso na identidade dos alunos nos exames ou colação de grau, o título de Faculdade seria cassado; e em caso de irregularidades ou abusos de outra natureza que enfraqueça o nível moral do ensino, poderia ocorrer a censura pública.

\subsection{Lei no 746, de 19 de dezembro de 1901: Código Epitácio Pessoa}

Esta lei foi chamada de Código Epitácio Pessoa por ser esse o Ministro da Justiça no governo Campos Sales, mas também professor da faculdade de Direito de Recife em $1891^{28}$. Estipulou o Código dos Institutos Oficiais de Ensino Superior e Secundário, em que em seu artigo 121 afirmava que: "é facultada a matrícula aos indivíduos do sexo feminino para as quais haverá nas aulas lugar separado ${ }^{29}$ ". Na prática anterior, excluía-se a mulher nos cursos jurídicos.

\footnotetext{
${ }^{27}$ BRASIL. Lei $n^{o}$ 314, de 30 de outubro de 1895. Op. cit. Acesso em 17 jun. 2015.

${ }^{28}$ VENANCIO FILHO, Alberto. Das Arcadas ao Bacharelismo: 150 anos de Ensino Jurídico no Brasil. São Paulo: Perspectiva, 1982, p. 201.
} 


\subsection{Decreto no 3.903 de 12 de janeiro de 1901}

Este decreto diferenciou a figura dos "lentes" com a dos professores. Lentes eram quem regiam as cadeiras, enquanto os professores quem regiam as aulas ${ }^{30}$.

José Sebastião de Oliveira [et. al] ${ }^{31}$ destaca que houve uma inovação no sentido de que foi autorizado que as mulheres pudessem fazer o exame de ingresso em curso jurídico, e se fossem aprovadas poderiam frequentar.

Este decreto estabeleceu que o curso jurídico deveria ser em 5 anos, refazendo as disciplinas do curso da seguinte forma ${ }^{32}$ : a) $1^{\text {a }}$ ano: Filosofia do Direito ( $1^{\text {a }}$ cadeira) e Direito romano ( $2^{\mathrm{a}}$ cadeira); b) $2^{\mathrm{o}}$ ano: Direito público e constitucional $\left(1^{\mathrm{a}}\right.$ cadeira), Direito internacional público e privado e diplomacia ( $2^{\mathrm{a}}$ cadeira) e Direito civil $-1^{\mathrm{a}}$ parte ( $3^{\mathrm{a}}$ cadeira); c) $3^{\mathrm{o}}$ ano: Direito civil $-2^{\mathrm{a}}$ parte $\left(1^{\mathrm{a}}\right.$ cadeira $)$, Direito criminal $-1^{\mathrm{a}}$ parte $\left(2^{\mathrm{a}}\right.$ cadeira $)$ e Direito comercial $-1^{\mathrm{a}}$ parte $\left(3^{\mathrm{a}}\right.$ cadeira); d) $4^{\mathrm{o}}$ ano: Direito civil $-3^{\mathrm{a}}$ parte $\left(1^{\mathrm{a}}\right.$ cadeira), Direito comercial, especialmente direito marítimo, falência e liquidação judicial $-2^{\mathrm{a}}$ parte $\left(2^{\mathrm{a}}\right.$ cadeira), Direito criminal, especialmente direito militar e regime penitenciário $-2^{\mathrm{a}}$ parte $\left(3^{\mathrm{a}}\right.$ cadeira) e Economia política, ciência das finanças e contabilidade do Estado (4 cadeira); e) $5^{\circ}$ ano: Teoria e pratico do processo civil, comercial e criminal ( ${ }^{\mathrm{a}}$ cadeira), Ciência da administração e direito administrativo ( $2^{\mathrm{a}}$ cadeira), Medicina pública ( $3^{\mathrm{a}}$ cadeira) e Legislação comparada do direito privado ( $4^{\mathrm{a}}$ cadeira).

Eliminou-se a disciplina de História do Direito, especialmente do Direito Nacional, porém mantém a disciplina do Direito romano ${ }^{33}$.

Os estudantes, professores e congregação organizaram protestos contra este Decreto, gritavam pelo ensino livre e pela pessoa de Leôncio de Carvalho, pois não simpatizaram com algumas medidas, tais como $^{34}$ : revogação do benefício de abono de faltas aos professores; a instituição da obrigatoriedade de arguições por 3 vezes ao mês, bem como a execução de trabalhos práticos pelos alunos a mando do professor ou lentes; o lente deveria fazer relatório mensal do diretor das lições e trabalhos práticos do mês anterior; estabelecimento de prova

\footnotetext{
30 BASTOS, Aurélio Wander. Op. cit., p. 166.

31 OLIVEIRA, José Sebastião de; TOFFOLI, Vitor. Op. cit., p. 8664.

${ }^{32}$ BRASIL. Decreto n. 3.903, de 12 de janeiro de 1901, que aprova o regulamento das Faculdades de Direito. Disponível em: <http://legis.senado.gov.br/legislacao/ListaTextoIntegral.action?id=44848\&norma=60599>. Acesso em 20 jul. 2015.

33 BASTOS, Aurélio Wander. Op. cit., p. 166.

34 VENANCIO FILHO, Alberto. Das Arcadas ao Bacharelismo: 150 anos de Ensino Jurídico no Brasil. São Paulo: Perspectiva, 1982, p. 202-204.
} 
prática e oral (a arguição duraria 30 minutos) para as disciplinas de Medicina Pública e de Teoria e Prática do Processo Civil e Criminal, sendo que a prova escrita teria duração de 2 horas; e 5 dias letivos por semana ao invés de 3 , entre outras.

Neste meio tempo, destaca-se que em 31 de março de 1902 surgiu a Faculdade Livre de Direito do Pará, influenciada pela Faculdade de Recife ${ }^{35}$.

\subsection{Decreto $n^{0} 8.659$, de 5 de abril de 1911}

Este decreto deu indícios de ${ }^{36}$ regulamentação das atividades privadas na educação superior, e proliferou as associações de ensino livre. Possuía ${ }^{37}$ o objetivo de retirar os privilégios (econômicos e financeiros) dos institutos criados pela União, dotando-os de personalidade jurídica para viabilizar sua autonomia; podendo receber legados e outros bens, bem como administrarem seu patrimônio, de forma que não poderia alienar nada sem autorização do governo.

Para tanto, adveio o artigo $3^{\circ}$ em que os institutos federais de ensino superior e fundamental passaram a possuir personalidade jurídica para receberem doações, legados e outros bens e administrarem seus patrimônios, não podendo, contudo, sem autorização do Governo, aliená-los.

Percebe-se no artigo $1^{\circ}$ do Decreto ${ }^{38}$ que as instituições superiores e fundamentais difundidas pelos institutos criados pela União, passaram a não gozar de privilégios de qualquer espécie. $\mathrm{O}$ artigo $2^{\circ}$ declarou que os institutos deixaram de ser subordinados ao Ministério do Interior, adquirindo sua autonomia didática e administrativa.

Organizou o ensino das faculdades através do disposto no artigo $4^{\circ}$, apontando que ${ }^{39}$ : nas faculdades de medicina do Rio de Janeiro e da Bahia seriam ministradas a cultura médica; já nas faculdades de Direito de São Paulo e de Pernambuco a cultura das letras jurídicas; na Escola Politécnica do Rio de Janeiro iria ministrar matemática superior e engenharia; e por fim no Colégio Pedro II se ensinariam as disciplinas do curso fundamental, com o seu desenvolvimento literário e científico.

\footnotetext{
35 VENANCIO FILHO, Alberto. Das Arcadas ao Bacharelismo: 150 anos de Ensino Jurídico no Brasil. São Paulo: Perspectiva, 1982, p. 204-205.

36 BASTOS, Aurélio Wander. Op. cit., p. 167.

37 BASTOS, Aurélio Wander. Op. cit., p. 167.

38 BRASIL. Decreto $n^{\circ} 8.659$, de 5 de Abril de 1911, que aprova a Lei Orgânica do Ensino Superior e do Fundamental na República. Disponível em: <http://www2.camara.leg.br/legin/fed/decret/1910-1919/decreto-8659-5-abril-1911-517247-republicacao-101878-pe.html> . Acesso em 20 jul. 2015.

39 BRASIL. Decreto $n^{\circ}$ 8.659, de 5 de Abril de 1911. Op. cit. Acesso em 20 jul. 2015.
} 
O controle sobre os Institutos de Ensino ${ }^{40}$ eram feitos pelo Ministério da Justiça e Negócios Interiores, porém com esse decreto o subtraiu da União e o transferiu ao Conselho Superior de Ensino; mas a retirada do controle das mãos do Ministério da Justiça e Negócios Interiores só veio a ocorrer efetivamente em 1931.

A figura da função fiscal do Estado foi substituída pelo Conselho Superior do Ensino criado pela presente lei, substituindo a função fiscal do Estado, oficializando-se totalmente o ensino e decretando sua independência da União (vide artigo $5^{\circ}$ ).

Através do artigo 12 percebe-se que é a primeira vez que os docentes puderam compor o quadro administrativo, pois "Foi nesta linha de diminuição de custos e identificação de políticas docentes mais flexíveis que, pela primeira vez, os docentes-livres incorporaramse à estrutura docente dos institutos $41 \%$. Destaca-se que isso representou um grande avanço administrativo aos docentes.

\subsection{Decreto $\mathrm{n}^{\circ}$ 8.662, de 5 de abril de 1911: Reforma Rivadávia Corrêa}

É também conhecido como a Reforma Rivadávia Corrêa. Estabeleceu-se na forma do art. $1^{\circ}$ que as Faculdades de Direito seriam regidas pela Lei Orgânica do Ensino e por este regulamento, sendo designadas pelo nome da cidade em que tiverem a sua sede.

A estrutura curricular do curso de Ciências Jurídicas e Sociais ficou com 6 anos de duração, distribuídos da seguinte forma: a) $1^{\text {a }}$ série: Introdução Geral do Estudo do Direito ou Enciclopédia Jurídica e Direito Público e Constitucional; b) $2^{\mathrm{a}}$ série: Direito Internacional Público e Privado e Diplomacia, Direito Administrativo e Economia Política e Ciência das Finanças; c) $3^{\mathrm{a}}$ série: Direito Romano, Direito Criminal (1 ${ }^{\mathrm{a}}$ parte) e Direito Civil (Direito de Família); d) $4^{\text {a }}$ série: Direito Criminal, (especialmente Direito Militar e Regime Penitenciário), Direito Civil (Direito Patrimonial e Direitos Reais) e Direito Comercial (1 ${ }^{\mathrm{a}}$ parte); e) $5^{a}$ série: Direito Civil (Direito das Sucessões), Direito Comercial (especialmente Direito Marítimo, falência e liquidação judicial) e Medicina Pública; f) 6a série: Teoria do Processo Civil e Comercial, Prática do Processo Civil e Comercial e Teoria e Pratica do Processo Criminal.

\footnotetext{
40 BASTOS, Aurélio Wander. Op. cit., p. 168

${ }^{41}$ BASTOS, Aurélio Wander. Op. cit., p. 168
} 
Houve mudanças com relação à disciplina de Filosofia do Direito, na forma do artigo 41, que foi precursora: “Art. 41. A cadeira de Filosofia do Direito fica transformada em cadeira de Introdução do Estudo do Direito ou Enciclopédia Jurídica e suprimida a cadeira de Legislação Comparada”.

De qualquer forma, foi com essa reforma que, pela primeira vez, se indicou o conteúdo das disciplinas de Direito Civil, especificando em suas aulas se ensinaria Direito de Família, Direito Patrimonial e Direitos Reais e Sucessões; por outro lado, ela reflete grande instabilidade no ensino da Prática Forense e a sua relação com o Processo. [...] estes currículos nunca falaram do ensino do Processo, mas da sua teoria. Continuava evidente a questão do ensino do Direito Processual; sem codificação não se ensinava Direito Processual, mas Teoria do Processo (Civil ou Criminal) ou Prática Forense ${ }^{42}$.

De acordo com Aurélio Wander Bastos 43 , essa reforma representou um grande avanço, pois a) deu autonomia corporativa às escolas; b) redefiniu a carreira do docente; c) introduziu exames para ingresso acadêmico; d) retomou-se o ensino de Direito Civil; acarretando a ruptura dos padrões do Império de ensino apenas a partir daqui.

\subsection{Decreto ${ }^{\circ} 11.530$ de 18 de março de 1915: Reforma Carlos Maximiliano}

Após a Reforma Rivadávia Corrêa que, como já mencionado, trouxe inúmeras mudanças e rupturas no ensino jurídico do País, promulgou-se o Decreto $\mathrm{n}^{\circ} 11.530$, de 18 de março de 1915, que ficou conhecido por Reforma Maximiliano por ter sido elaborada pelo jurista Carlos Maximiliano ${ }^{44}$, então Ministro da Justiça e Negócios. Tal reforma foi assinada pelo Presidente Wenceslau Braz, tendo por objetivo reorganizar o ensino secundário e superior na República.

Através desse novo decreto o curso de Direito sofreu nova reforma curricular, bem como se viabilizou a criação de um instituto de ensino jurídico oficial na cidade do Rio de Janeiro, o que acabou provocando a fusão das faculdades livres existentes.

\footnotetext{
42 BASTOS, Aurélio Wander. Op. cit., p. 169-170.

43 BASTOS, Aurélio Wander. Op. cit., p. 170.

44 Carlos Maximiliano Pereira dos Santos nasceu em 24 de abril de 1873, em São Jerônimo, província do Rio Grande do Sul. Fez o curso de Humanidades em Porto Alegre e formou-se em Ciências Jurídicas e Sociais na Escola de Direito de Belo Horizonte, recebendo o grau de Bacharel em março de 1898. Convidado pelo Dr. Wenceslau Braz Pereira Gomes para auxiliar do seu governo presidencial, iniciado em 15 de novembro de 1914, aceitou a pasta da Justiça e Negócios Interiores sendo nomeado na referida data. Dot ado de grande cultura e brilhante inteligência, organizou vários serviços, dentre eles o alistamento e processo eleitoral, o ensino secundário e superior da República. Carlos Maximiliano foi o ministro que referendou o Código Civil Brasileiro e a Consolidação das disposições legais e regulamentares concernentes aos territórios das freguesias urbanas e suburbanas do Distrito Federal, que formaram as circunscrições judiciárias das pretorias. SUPREMO TRIBUNAL FEDERAL. Carlos Maximiliano Pereira dos Santos. Disponível em: <http://www.stf.jus.br/portal/ ministro/verMinistro.asp?periodo=stf\&id=230>. Acesso dia: 20/07/2015.
} 
Vale lembrar que até essa época não havia ainda qualquer faculdade oficial naquela cidade, de forma que todos os bacharéis que ali eram formados pelas faculdades livres precisavam reconhecer seus diplomas em uma das faculdades oficiais (em Pernambuco ou São Paulo).

No Estado do Paraná ${ }^{45}$ Alberto Venancio Filho afirma que havia a universidade criada em 1912, porém com a Reforma Maximiliano a mesma foi dissolvida, surgindo então outras três faculdades: de Direito (a primeira a ser reconhecida em 1920), de Engenharia e de Medicina.

Referido decreto estabelecia ainda em seu artigo 99 que "Não haverá alunos gratuitos nos institutos de ensino superior", o que, nas palavras de Aurélio Wander Bastos significava “[...] que o ensino seria oficial, mas não seria propriamente gratuito, devendo o aluno pagar taxas de matrícula e frequência, por todo o ano escolar"46.

Com as mudanças trazidas por Maximiliano, o curso de Direito diminuiu a duração para 5 anos, compreendendo as seguintes matérias: a) $1^{\circ}$ ano: Filosofia do Direito, Direito Público e Constitucional, Direito Romano; b) $2^{\circ}$ ano: Direito Internacional Público, Economia Política e Ciências das Finanças, Direito Civil ( $1^{\circ}$ ano); c) $3^{\circ}$ ano: Direito Comercial $\left(1^{\circ}\right.$ ano), Direito Penal ( $1^{\circ}$ ano), Direito Civil ( $2^{\circ}$ ano); d) $4^{\circ}$ ano: Direito Comercial ( $2^{\circ}$ ano), Direito Penal ( $2^{\circ}$ ano), Direito Civil ( $3^{\circ}$ ano), Teoria do Processo Civil e Comercial; e) $5^{\circ}$ ano: Prática do Processo Civil e Comercial, Teoria e Prática do Processo Criminal, Medicina Pública, Direito Administrativo, Direito Internacional Privado.

Insta ressaltar que uma das preocupações centrais dessa reforma era incentivar um curso prático, que ensinasse a redigir atos jurídicos e a organizar a defesa de direitos, tal como explicitado no art. 175 do referido decreto. A propósito:

\begin{abstract}
Apesar de a disciplina Prática do Processo já ser oferecida na época do Império, é neste decreto que, pela primeira vez, fica explicitamente manifesta a intenção de se incentivar, com específicas identificações de programa, um ensino prático, o que significa, neste ponto, uma evolução em relação à Lei Rivadávia 47 .
\end{abstract}

\footnotetext{
45 VENANCIO FILHO, Alberto. Das Arcadas ao Bacharelismo: 150 anos de Ensino Jurídico no Brasil. São Paulo: Perspectiva, 1982, p. 212.

46 BASTOS, Aurélio Wander. Op. cit., p. 171.

47 BASTOS, Aurélio Wander. Op. cit., p. 173.
} 
Além disso procurou-se vincular a matéria sucessiva ao professor que havia ensinado a matéria antecedente, dessa forma todos os módulos de direito civil, por exemplo, seriam dados pelo mesmo professor. Foi também com essa nova reforma que se alterou o nome da disciplina de Direito Criminal para Direito Penal.

Contudo, tecendo uma comparação com a Reforma Rivadávia Corrêa, pode-se afirmar que, embora historicamente anterior, a Rivadávia trouxe aspectos mais modernos e avanços mais significativos ao ensino jurídico do que a reforma de Carlos Maximiliano. Como exemplo podemos destacar a criação de um Conselho de Curso Superior pela Reforma de 1911, que não obstante possuísse significativa importância para a educação no País, acabou perdendo suas funções com a promulgação do Decreto de Carlos Maximiliano.

Ademais, no que diz respeito ao currículo adotado, a Reforma Rivadávia foi ousada: trouxe pela primeira vez a disciplina da Introdução Geral ao Estudo do Direito; bem como deslocou o Direito Romano das disciplinas básicas formativas, afastando de certo modo um pouco da influência europeia no ensino jurídico do Brasil. Todavia com a nova reforma, de natureza mais tradicional, não só retornou o Direito Romano, como também eliminou a disciplina de Introdução ao Estudo do Direito, decisões essas consideradas como um retrocesso no ensino jurídico.

Também foi através desse Decreto de Carlos Maximiliano, especialmente o seu artigo $6^{\circ}$, que deu início ao processo de criação da primeira universidade brasileira. $\mathrm{O}$ mencionado dispositivo assim estabelecia: "O governo Federal, quando achar oportuno, reunirá em Universidade as escolas Politécnicas e de Medicina do Rio de Janeiro, incorporando a elas uma das Faculdades livres de Direito, dispensando-a de taxa de fiscalização e dando-lhe, gratuitamente edifício para funcionar". E foi desta forma que ocorreu.

A possibilidade de incorporação de uma faculdade de Direito a uma universidade, fez surgir, cerca de 100 anos após a criação das duas únicas faculdades oficiais do País (em Recife e em São Paulo), uma terceira faculdade de Direito oficial, o que se deu com a fusão de duas escolas livres do Rio de Janeiro.

\subsection{Decreto $\mathrm{n}^{\circ} \mathbf{1 4 . 1 6 3}$, de 12 de maio de 1920}

Assim, em 12 de maio de 1920, promulgou-se o Decreto $\mathrm{n}^{\circ} 14.163$ que fundiu a Faculdade de Ciências Jurídicas e Sociais e a Faculdade Livre de Direito da Capital Federal em uma só instituição, agora sob a denominação de Faculdade de Direito do Rio de Janeiro. 
Diante disso:

Vencida essa etapa, estavam criadas as condições para o incentivo à criação de uma universidade na cidade do Rio de Janeiro, então Distrito Federal, ou, pelo menos para se traçar uma política universitária para o Brasil.

Posteriormente, passados três meses da oficialização da Faculdade de Direito do Rio de Janeiro, foi instituída a Universidade do Rio de Janeiro, por força do Decreto $\mathrm{n}^{\mathrm{o}}$ 14. 343, de 07 de setembro de 1920, assinado por Epitácio Pessoa e Alfredo Pinto Vieira de $\mathrm{Melo}^{48}$.

Referido momento também foi registrado por Luiz Antônio Bove:

Somente em 1920, pelo Decreto n. 14343, de 7 de setembro de 1920, do Presidente da República, Dr. Epitácio Pessoa, surgiu a Universidade do Rio de Janeiro, que viria a ser, mais tarde, a Universidade Federal do Rio de Janeiro, organizada mediante a reunião dos cursos superiores existentes na cidade, a saber: a Escola Politécnica, a Faculdade de Medicina e a Faculdade de Direito, esta nascida da fusão de duas outras, Faculdade Livre de Direito e a Faculdade de Ciências Jurídicas e Sociais, dois cursos privados sem maior expressão 49 .

Neste momento, cumpre esclarecer que há uma polêmica em torno de qual teria sido de fato a primeira universidade do Brasil; se a do Rio de Janeiro, criada em 1920, ou a do Paraná, criada em 1912.

Para José Sebastião de Oliveira [et. al], a primeira universidade do Brasil foi criada em Curitiba:

A primeira Universidade do Brasil, contudo, de fato, só foi criada em 1912 em Curitiba, e de direito, foi em 1920, na cidade do Rio de Janeiro, que hoje é a Universidade Federal do Rio de Janeiro, uma das mais importantes do Brasil (apesar de fortes divergências sobre qual delas realmente foi a pioneira) ${ }^{50}$.

Da mesma opinião, Alberto V. Filho ${ }^{51}$ afirma que no estado do Paraná o curso jurídico surgiu na Universidade criada em 19 de dezembro de 1912, justamente devido à facilitação atribuída pela Reforma Rivadávia Corrêa, bem como os cursos de Engenharia, Odontologia Obstetrícia e Comércio, Farmácia, e em 1914 o de Medicina.

O que se depreende, na realidade, é que não obstante a Universidade de Curitiba tenha sido criada anteriormente a do Rio de Janeiro, ela apenas foi reconhecida mais tarde, em 1946, de forma a se considerar a Universidade do Rio de Janeiro como a primeira de Direito do Brasil.

\footnotetext{
48 BASTOS, Aurélio Wander. Op. cit., p. 178.

49 BOVE, Luiz Antônio. Uma visão histórica do ensino jurídico no brasil. In: Revista do Curso de Direito. São Paulo, v. 3, n. 3, 2006, p. 121-122.

50 OLIVEIRA, José Sebastião de; TOFFOLI, Vitor. Op. cit., p. 8671-8672.

51 VENANCIO FILHO, Alberto. Das Arcadas ao Bacharelismo: 150 anos de Ensino Jurídico no Brasil. São Paulo: Perspectiva, 1982, p. 212.
} 
Com a primeira Universidade criada, na antevéspera da Revolução de 1930, comemorava-se o centenário da criação das Faculdades de Olinda e de São Paulo. Em razão disso, César Vergueiro apresentou o Projeto $n^{\circ} 9$ de 1927 que, entre outros objetivos, concedeu às citadas faculdades a quantia de cem contos de réis a cada uma como comemoração. Além disso o citado projeto pretendia demonstrar a importância de tais faculdades na história do Brasil e na formulação de novas instituições de ensino. Segundo Vergueiro, os bacharéis advindos de tais cursos influenciaram na democratização das estruturas autocráticas imperiais.

Todavia, apesar de ressaltadas as importâncias, conquistas e evoluções desse centenário, nem tudo eram flores. Nesse mesmo período, “[...] o Brasil chegou, à época do primeiro centenário do curso de Direito em 1927 com 14 cursos de Direito 3200 alunos matriculados" 52 . A partir de então houve um aumento indiscriminado de vagas no Ensino Jurídico Brasileiro, inclusive de instituições particulares, sem se ter notícias de modificações qualitativas no mesmo, o que fez por crescer ainda mais as críticas a esse período de ensino.

Vale lembrar que os bacharéis de Direito oriundos das elites dirigentes, até então em sua grande maioria, começaram a advir também de uma classe média em ascensão, resultando em uma diversidade de postos de trabalho; agora não mais apenas ocupados na burocracia estatal, mas em empresas ou como profissionais liberais.

Ocorre que a criação de novas escolas era realizada sem o menor critério e, segundo Alberto Venâncio Filho:

Tal movimento que já foi chamado ironicamente de 'inchação' do ensino superior, ou 'política de cogumelagem', ocorreu num período em que as transformações econômicas do país, com a atenção para os problemas de planejamento econômico e de uma intervenção mais ordenada do estado nas atividades econômicas, estariam a exigir um ensino superior de tipo novo, inclusive em ensino de Direito que atentasse para as novas realidades sociais 53 .

O que se constatou na realidade foi que, em que pese o aumento das vagas e de instituições de ensino, os critérios de modificação do currículo jurídico eram absolutamente aleatórios e a sua filosofia remanescia a mesma do período imperial. Outrossim: "Os currículos jurídicos da primeira república não foram inovadores e não trouxeram para as

\footnotetext{
52 OLIVEIRA, José Sebastião de; TOFFOLI, Vitor. Op. cit., p. 8672.

53 VENANCIO FILHO, Alberto. Das Arcadas ao Bacharelismo: 150 anos de Ensino Jurídico no Brasil. São Paulo: Perspectiva, 1982, p. 312-313
} 
faculdades nem ao menos a marca do pensamento positivista, que influiu no movimento republicano e nas providencias institucionais dos primeiros anos da Republica ${ }^{54}$ ".

A propósito, também é de se destacar as considerações de Luiz Antônio Bove:

[...] essas faculdades deixavam, na oportunidade de suas implantações, muito a desejar quanto à qualidade do ensino jurídico ministrado. Devendo ser ressalvado que integrava nessa época, entre outros acadêmicos, grandes poetas e escritores como: Álvares de Azevedo, Castro Alves, Fagundes Varela, Bernardo Guimarães, em São Paulo, e Sílvio Romero, Tobias Barreto, entre outros, em Pernambuco 55.

Ora, ainda que considerando as várias alterações legislativas realizadas até chegar-se aos anos trinta, “[...] as reformas republicanas, excetuando-se a exclusão do Direito Natural e do Direito Eclesiástico, não são indicativas de grandes mudanças nos ideais curriculares ${ }^{56}$, como bem ressaltou Flávio Bento [et. al].

Assim pode-se afirmar que esse período da República Velha caracteriza-se por manter uma base românica do ensino, uma resistência ao Direito Constitucional e um desinteresse pelo ensino da Introdução Geral ao Direito, bem como da Economia Política, disciplinas estas formadoras de uma natureza crítica ou científica.

Nas palavras de Venâncio Filho, “A República seria, do ponto de vista administrativo, uma sucessão de reformas, umas se seguindo às outras, com a mera modificação das matérias, mas sem nenhum princípio basilar, sem nenhuma ideia orientadora ${ }^{57}$ ”.

Nesta oportunidade, apenas a título de contextualização histórica, é importante constar o momento histórico vivenciado no país em outros setores. No período que vai de 1915 a 1930, por exemplo, o Brasil passou por diversas crises, com revoltas populares lideradas por facções políticas e dos Estados membro; havia grande conflito de interesses, especialmente do poder econômico e político dos Estados do Rio Grande do Sul, São Paulo, Minas Gerais e Bahia. Ademais, no âmbito mundial havia grande instabilidade resultante do crash da Bolsa de Nova Iorque. Por fim, com a reeleição de Washington Luiz, a forte oposição impôs um golpe em 24 de outubro de 1930, tomando posse o Governo Provisório de Getúlio Vargas, que pôs fim à República Velha ou Primeira República, que foi de 1889 a 1930.

\footnotetext{
54 BASTOS, Aurélio Wander. Op. cit., p.172.

55 BOVE, Luiz Antônio. Op. cit., p. 07.

56 BENTO, Flávio; SANCHES, Samyra Haydêe Dal Farra Naspolini. A história do ensino do direito no brasil e os avanços da portaria 1886 de 1994. In: XVIII Congresso Nacional CONPEDI, 2009, São Paulo. Anais do XVIII Congresso Nacional do CONPEDI. Florianópolis: Fundação Boiteux, 2009. v. 1, p. 11.

57 VENANCIO FILHO, Alberto. Análise histórica do ensino jurídico no Brasil. In: Encontros da UnB: Ensino Jurídico. Brasília: Editora Universidade de Brasília, 1978-1979, p. 27-28.
} 


\title{
3 A Metodologia de ENSINO E FILOSOFiA ADOTADA NO PERÍODO DA REPÚBLICA VELHA
}

No que diz respeito à metodologia, o resultado não foi diferente. Considerando que não houve ou foi insubsistente qualquer tentativa de avanço pedagógico, o resultado natural foi sua inclinação para a pedagogia tradicional. Acerca dessas deficiências de ensino e metodologia do período, faz-se destaque: "As demais escolas criadas durante este período repetiam as mesmas deficiências e os mesmos problemas das escolas tradicionais. A docência permanecia sem ser a atividade principal dos professores das faculdades que limitavam seu método à leitura dos compêndios ${ }^{58}$ ".

Coaduna com tal opinião Antônio A. Machado ${ }^{59}$, que diz que a partir do século XIX a cultura jurídica que predominava entre os profissionais do direito é o puro conhecimento da normatividade e técnicas de aplicação da lei na época vigente; porém acredita que tal postura seria a mais adequada para solucionar conflitos interindividuais (privados), mas insuficiente para enfrentar as realidades futuras.

Ademais, faz-se importante ressaltar:

\begin{abstract}
Essa fase encerra um momento de afirmação do Liberalismo na sociedade brasileira, cristalizado nos cursos de Direito por meio da baixa estruturação metodológica e do direcionamento privatista das grades curriculares. Isso contribuiu para a formação de um ciclo de reprodução da ideologia liberal na formação jurídica dos operadores brasileiros do Direito, contribuindo oportunamente para o surgimento do termo "fábricas de bacharéis"60.
\end{abstract}

E mais: “A Proclamação da República, como também ocorreu com a abolição da escravatura, não foi fruto de grandes transformações sociais vinculadas a ideais liberais e revolucionários. Pelo contrário, tratou-se de um episódio que transcorreu à parte da maioria da população ${ }^{61 \%}$.

\footnotetext{
58 BENTO, Flávio; SANCHES, Samyra Haydêe Dal Farra Naspolini. Op. cit., p. 10.

59 MACHADO, Antônio Alberto. Op. cit., p. 181.

${ }^{60}$ MARTINEZ, Sérgio Rodrigo. A evolução do ensino jurídico no Brasil. Revista Jus Navigandi, Teresina, ano 11, n. 969, 26 fev. 2006. Disponível em: <http://jus.com.br/artigos/ 8020/a-evolucao-do-ensino-juridico-no-brasil\#ixzz3gedUPfAe>. Acesso em 13 jun. 2015.

61 BENTO, Flávio; SANCHES, Samyra Haydêe Dal Farra Naspolini. Op. cit., p. 9.
} 
José Reinaldo de Lima Lopes ${ }^{62}$ afirma que entre os bacharéis neste período predominava-se a filosofia do liberalismo principalmente com Rui Barbosa, ou seja, focava-se na individualidade, tendo uma sociedade dividida e antidemocrática; e ainda com uma grande admiração pelo direito privado alemão.

Antônio A. Machado ${ }^{63}$ afirma que com a proclamação da República, os bacharéis começaram a pensar no Estado de Direito e sobre participação política com base no liberalismo clássico; bem como acreditavam no positivismo comteano (como por exemplo a frase "Ordem e Progresso" da bandeira do Brasil) e no evolucionismo darwinista para a reprodução do conhecimento jurídico.

Marcelo Mesquita assevera que:

Com a proclamação da república também pouca coisa mudou, o ensino jurídico no Brasil continuou extremamente conservador, tecnicista e dogmático, distante da realidade social do país e sem despertar no discente um olhar crítico e consciente do seu papel como agente de transformação. Prova maior disso é que, no Brasil, desde 1827, quando surgiram os primeiros cursos jurídicos, até 1962, já na república, o currículo do curso de Direito era único, rígido e invariável, com pequenas modificações quando do advento da república em razão do processo de laicilização e da influência do positivismo, demonstrando o forte controle político-ideológico 64 .

Como pode-se constatar, durante essa fase da primeira República o ensino jurídico praticamente manteve as mesmas características imperiais, tendo sido modificado apenas após 1930, quando então surgiu uma nova estrutura pedagógica, o que se deu com as reformas perpetradas por Francisco Campos e Gustavo Capanema entre os anos de 1930 e 1937.

Dessa forma, com reformas atrás de reformas, o ensino jurídico, após o findar da terceira década do Século XX, não se diferenciava muito daquele ensinado cerca de cem anos atrás. Ou seja, os profissionais formados à essa época eram, em sua grande maioria, acríticos e meros repetidores de ideias.

\footnotetext{
62 LOPES, José Reinaldo de Lima. O direito na história: lições introdutórias. 3. ed. São Paulo: Atlas, 2011, p. 341-344.

63 MACHADO, Antônio Alberto. Op. cit., p. 133-134.

64 MESQUITA, Marcelo Rocha. O perfil ideal do graduando em direito: sugestões para a sua obtenção. In: XXIII Congresso Nacional do CONPEDI, 2014, João Pessoa. Direito, ensino e metodologia jurídicos I. XXIII Congresso Nacional do CONPEDI. Florianópolis: CONPEDI, 2014. p. 397.
} 
[...] o curso de Olinda-Recife voltou-se mais a formação de magistrados, promotores, da força de trabalho pública, ao passo que o curso de São Paulo serviu mais à formação da elite política brasileira, chegando a ser intitulada de República dos Bacharéis, com nove futuros presidentes formados nas Arcadas 65 .

Relembrando a Reforma Benjamin Constant já mencionada, foi visto que esta determinava que as Faculdades de Direito deviam ter 3 cursos: o de Ciências Jurídicas, Ciências Sociais e de Notariado. Com isso, pode-se dizer que o objetivo do bacharelado na época era de se formar profissionais nos seguintes ramos:

\begin{abstract}
A obtenção do grau de bacharel em Ciências Jurídicas habilitava o aluno, na forma dessa lei, para o exercício da advocacia, da magistratura e dos ofícios de justiça; o de bacharel em Ciências Sociais, para os cargos do corpo diplomático e consular, os de diretor, subdiretor e oficial de diretorias de governo e administração; e o Curso de Notariado habilitava para os ofícios de justiça, assim como o de Ciências Jurídicas. Era permitida também a habilitação em outros desses três cursos, sucessivamente, à habilitação no anterior, sendo que o grau de doutor em Ciências Jurídicas e Sociais podia ser conferido a todos que, "tendo o de bacharel em ambos os cursos" (Ciências Jurídicas e Sociais), defendessem tese pela forma estabelecida neste regulamento. Diferentemente da instalação dos cursos jurídicos no Brasil, e suas sucessivas reformas, o primeiro currículo republicano não traduz debates parlamentares nem discussões pedagógicas profundas 66 .
\end{abstract}

Ou seja, tomou corpo a ideia de se desenvolver no período da República Velha um curso voltado para a formação de advogados, magistrados e promotores. Com a República, até 1879 o curso começou realmente a destinar-se à formação de bacharéis advogados, mas continuava com a mesma marca de anteriormente, qual seja, um curso que forma advogados destinados igualmente a formar a elite institucional e política brasileira ${ }^{67}$. Ou seja, a elite do pensamento humanístico.

Porém houve mudança no perfil com a Lei no 314 de 30 de outubro de 1895, pois como dito anteriormente através desta surgiu o curso de Ciências Jurídicas e Sociais. Focava- se na atuação da advocacia, magistratura e ofícios de justiça, bem como para cargos do corpo diplomático e consular, conforme o Decreto regulamentar $\mathrm{n}^{\circ} 2.226$, de 1 de fevereiro de 1896. E de acordo com Aurélio Wander Bastos:

65 OLIVEIRA, José Sebastião de; TOFFOLI, Vitor. Op. cit., p. 8670.

66 BASTOS, Aurélio Wander. Op. cit., p. 155.

67 BASTOS, Aurélio Wander. Op. cit., p. 165. 
[...] desloca oficialmente a formação de servidores públicos internos e cartorários e da diplomacia, exclusivamente para os cursos de Direito, hipertrofiando a sua presunção vocativa de formar advogados e magistrados também em unidade de formação de servidores públicos. Estava extinta no Brasil a proposta que se desenvolvera a partir de 1879 de formar elites administrativas em curso de Ciências Sociais ou Notariado, conexo ao curso de Direito. Dessa forma, o curso de Direito, formulado como curso para a formação de advogados e magistrados, inicia-se como unidade de formação da elite administrativa, restaurada a proposta da sua criação em 1827 e que perdurara até $1879^{68}$.

A Reforma Carlos Maximiliano incumbiu-se não só da função formativa de advogados, juízes e outros servidores da justiça, mas também da formação de servidores da Administração e da Diplomacia, profissões estas anteriormente tratadas em estrutura curricular própria - que era o curso de Ciências Sociais.

Complementando, Antônio A. Machado diz que o modelo de profissional no período republicano era baseado em noções liberais, tais como: “[...] sufrágio universal, democracia representativa, igualdade jurídica, primado da lei, repartição dos poderes etc ${ }^{69}$ "

Antônio Alberto Machado afirma:

[...] o estereótipo do profissional da advocacia sempre se amoldou perfeitamente aos preceitos do liberalismo individualista. Ou seja, o advogado sempre foi aquele que devia falar em nome do indivíduo singularmente considerado (daí a expressão ad vocare), na defesa dos interesses particulares daquele que o constituiu, frente a quaisquer interferências do Estado ou de quem quer que fosse. Esse foi o perfil da profissão desde os primórdios do Brasil Colônia, quando nossos advogados se formavam em Coimbra, passando pelo Império e até durante a República Velha. A partir da revolução de 30, quando o país começa a se desenvolver como nação tipicamente capitalista, começa também a se modificar o papel dos bacharéis em direito e, entre eles, o papel do advogado. Até então, o profissional da advocacia nunca teve outros objetivos que não os de defesa do interesse individual, às vezes até mesmo contra o interesse público, coletivo ou social ${ }^{70}$.

Assim, nota-se que a mudança significativa do perfil foi apenas a partir de 1930, com a Era Vargas, assumindo um contexto mais capitalista. Até então, o perfil do profissional do Direito era individualista, preocupado apenas com a literalidade da lei.

68 BASTOS, Aurélio Wander. Op. cit., p. 165.

69 MACHADO, Antônio Alberto. Op. cit., p. 133-134.

70 MACHADO, Antônio Alberto. Op. cit., p. 185. 


\section{AS PRINCIPAIS FIGURAS JURÍDICAS}

Por fim, cumpre destacar que as principais figuras do ensino jurídico dessa época foram: Pontes de Miranda (com a obra "Sistema de Ciência positiva de Direito" - 1922; “Introdução a Sociologia Geral” - 1926; “Tratado de Direito privado”), Clóvis Beviláquia (autor do projeto do Código Civil de 1916), Arthur Orlando, Tobias Barreto, Epitácio Pessoa, Silvio Romero, Rui Barbosa ${ }^{71}$ (escrevendo na área da educação), entre outros.

Sergio Adorno ${ }^{72}$ aponta alguns professores lentes da Faculdade de Direito de São Paulo que se destacaram por seus cargos e pela produção de conhecimento: a) Joaquim Inácio Ramalho, de 1836 a 1883 com a cadeira de Teoria e prática do Processo Civil e Comercial, tendo escrito várias obras (Instituições Orfanológicas, Praxe Brasileira, Elementos do Processo Criminal e o Tratado sobre as fontes do Direito Pátrio em coautoria); b) Francisco Maria de Souza Furtado de Mendonça de 1839 a 1882 com a cadeira de Direito Administrativo, autor de obras (Repertório das Leis no Brasil, Excerto de Direito Administrativo Pátrio, Anotações do Tratado dos Testamentos de Gouveia Pinto, Anotações ao Código do Processo Criminal e Conselheiro Fiel do Povo); c) João da Silva Carrão, com a cadeira de Direito Natural e Economia Política de 1845 até 1881, porém sem obra publicada; d) Martim Francisco Ribeiro de Andrada com a cadeira de Direito Eclesiástico e Direito Natural no período de 1854 à 1886, também sem nenhuma obra publicada; e) José Bonifácio de Andrada e Silva, na cadeira de Direito Civil e Direito Criminal no período de 1858 à 1886, sem publicação alguma; entre outros.

Outra lista apresentada pelo mesmo autor ${ }^{73}$ destaca alguns bacharéis pela Faculdade de Direito de São Paulo, que se notabilizaram na vida pública: a) Pedro Augusto Carneiro Lessa (da turma de 1879-1883, com doutoramento em 1888); b) Afonso Celso de Assis Figueiredo Junior (turma de 1876-1881, com doutoramento no ano de 1882); c) Joaquim Francisco de Assis Brasil (turma de 1878-1882); d) Eduardo Prado (turma de 1877-1881); e) João Brás de Oliveira Arruda (turma de 1877-1881), entre outros.

\footnotetext{
71 CORDEIRO NETO, Holmes; AMORIM, Rosendo Freitas de. Op. cit., p. 516.

72 ADORNO, Sérgio. Os aprendizes do poder: o bacharelismo liberal na política brasileira. Rio de Janeiro: Paz e Terra, 1988, p. 125-127.

73 ADORNO, Sérgio. Op. cit., p. 137.
} 
Alberto Venancio Filho ${ }^{74}$ destaca que na primeira turma da Faculdade Livre de Direito de Porto Alegre há várias figuras que merecem destaque: Carlos Martins Pereira de Souza (teve posteriormente atuação no serviço diplomático brasileiro, formando-se na primeira turma desta faculdade) e João Neves da Fontoura (formou-se no período de 1905-

1909, escrevendo a obra Memórias).

Estas foram apenas alguns profissionais que marcaram a trajetória do curso de Direito, não havendo a possibilidade de citar todos os que foram relevantes para a construção teórica, doutrinária e legislativa.

\section{CONSIDERAÇÕES FINAIS}

Procurou-se com o presente trabalho analisar as principais reformas do ensino jurídico do Brasil, a fim de capacitar a compreensão dos problemas enfrentados na instalação de uma faculdade e universidade no país, bem como de uma grade curricular condizente com o perfil do profissional na época.

Primeiramente, o Decreto $\mathrm{n}^{\circ} 10.361$, de 14 de novembro de 1890 foi significativo para o ensino do Direito no Brasil, pois retirou a cadeira de Direito Eclesiástico do currículo dos cursos jurídicos das cidades de Recife e São Paulo, separando definitivamente a Igreja do Estado.

A Reforma Benjamin Constant (Decreto ${ }^{\circ} 1.232 \mathrm{H}$ de 2 de janeiro de 1891) permitiu a abertura de cursos livres nas Faculdades Federais, podendo haver a abertura cursos ou estabelecimentos por particulares ou associação de particulares. A grade curricular do curso de Ciências Jurídicas foi montada para ser finalizada em 4 séries, trocando o ensino do Direito Natural para o de Filosofia do Direito, História do Direito e História do Direito Nacional. Nesta época não se estimulava o estudo de Direito Processual.

O Decreto n ${ }^{\circ} 639$, de 31 de outubro de 1891, concedeu-se o título de Faculdade Livre à Faculdade Livre de Ciências Jurídicas e Sociais do Rio de Janeiro e à Faculdade Livre de Direito da Capital, com os mesmos privilégios e garantias das Faculdades Federais.

\footnotetext{
74 VENANCIO FILHO, Alberto. Das Arcadas ao Bacharelismo: 150 anos de Ensino Jurídico no Brasil. São Paulo: Perspectiva, 1982, p. 193.
} 
Após, o Decreto $\mathrm{n}^{\mathrm{o}} 1.159$, de 3 de dezembro de 1892 estabeleceu que as duas faculdades de Direito (localizadas em São Paulo e Pernambuco) seriam mantidas pelo governo.

A Lei $\mathrm{n}^{\mathrm{o}}$ 314, de 30 de outubro de 1895 decretou o fechamento do curso de Ciências Sociais e de Notariado, devendo aquele funcionar por mais dois anos, e este por mais um ano, consolidando apenas um único curso: o de Ciências Jurídicas e Sociais. Alterou novamente a grade curricular, com duração de 5 anos. Restabeleceu-se a frequência, melhorou o aproveitamento dos alunos e as condições de ensino.

O Código Epitácio Pessoa (Lei $n^{\circ} 746$, de 19 de dezembro de 1901) facultava às mulheres o acesso ao ensino jurídico, sendo que deveriam ter aulas em lugar separado.

Já o Decreto nº 3.903 de 12 de janeiro de 1901 autorizou que as mulheres fizessem o exame de ingresso em curso jurídico, bem como permitiu que pudessem frequentá-lo. O curso jurídico tinha a duração de 5 anos, eliminou a disciplina de História do Direito, especialmente do Direito Nacional, mas manteve a de Direito romano. Os estudantes, professores e congregação organizaram protestos contra esta lei e gritavam pelo ensino livre e pela pessoa de Leôncio de Carvalho, tendo em vista terem sido adotadas medidas contra o interesse dessas.

O Decreto $\mathrm{n}^{\circ}$ 8.659, de 5 de abril de 1911 deu indícios para regulamentar as atividades privadas na educação superior, e proliferou as associações de ensino livre. Retirou os privilégios (econômicos e financeiros) dos institutos criados pela União, dando-os personalidade jurídica para viabilizar sua autonomia; bem como os institutos deixaram de ser subordinados ao Ministério do Interior, adquirindo sua autonomia didática e administrativa.

A Reforma Rivadávia Corrêa (Decreto $n^{\circ}$ 8.662, de 5 de abril de 1911) adotou pela primeira vez a disciplina da Introdução Geral ao Estudo do Direito, bem como deslocou o Direito Romano das disciplinas básicas formativas, afastando a influência europeia no ensino. A estrutura curricular do curso de Ciências Jurídicas e Sociais ficou com duração de 6 anos

Todavia, com a reforma Carlos Maximiliano (Decreto $\mathrm{n}^{\circ} 11.530$ de 18 de março de 1915), o curso de Direito diminuiu para 5 anos, e como havia uma natureza mais tradicional, retornou a disciplina de Direito Romano e eliminou a de Introdução ao Estudo do Direito, decisões essas consideradas como um retrocesso no ensino jurídico. Ainda, a partir daqui é que se deu início ao processo de criação da primeira universidade brasileira.

Porém, vale ressaltar a polêmica do surgimento da primeira universidade do Brasil, adotando-se a posição de que a de Curitiba, muito embora tenha sido criada em 1912, fora 
apenas reconhecida em 1946. Portanto, a primeira universidade do Brasil foi a do Rio de Janeiro, criada em 1920.

O Decreto $n^{\circ}$ 14.163, de 12 de maio de 1920, fundiu a Faculdade de Ciências Jurídicas e Sociais e a Faculdade Livre de Direito da Capital Federal em uma só instituição, denominando-a de Faculdade de Direito do Rio de Janeiro.

Nas escolas de Recife e de Olinda, os bacharéis seguiam a magistratura, a promotoria, cargos públicos. Com a Reforma Benjamin Constant (Decreto $\mathrm{n}^{\circ} 1.232 \mathrm{H}$ de 2 de janeiro de 1891), destaca-se que o perfil do profissional do curso de Ciências Jurídicas era de formar para ofícios da justiça, advogados e magistrados. Já o curso de Ciências Sociais, a formação era para ocupação dos cargos diplomático, consular, os de diretor, subdiretor e oficial de diretorias de governo e administração.

Com a Lei $\mathrm{n}^{\mathrm{o}} 314$ de 30 de outubro de 1895, o profissional se dirigia aos cargos de servidores públicos internos, cartorários e da diplomacia, diminuindo o enfoque à magistratura e advocacia.

O liberalismo assumia uma posição significativa no direito, bem como o positivismo, fazendo com que o bacharel se encarregasse apenas de uma visão literal da lei, despreocupado com os problemas sociais que assolavam o país.

A mudança significativa do perfil foi apenas a partir de 1930, com a Era Vargas, assumindo uma visão mais capitalista, pois até então o perfil do profissional do Direito era individualista, preocupado apenas com a literalidade da lei.

Os profissionais que foram importantes para a trajetória do curso de Direito no Brasil foram: Pontes de Miranda, Clóvis Beviláquia, Arthur Orlando, Tobias Barreto, Epitácio Pessoa, Silvio Romero, Rui Barbosa, entre outros.

Por fim, pôde-se constatar as mudanças mais significativas no curso de Direito no Brasil no período da República Velha, muitas das quais foram necessárias para que se chegasse ao ensino adotado atualmente. Porém, foram inúmeras reformas, sendo inicialmente focada na elite brasileira e posteriormente voltada ao capitalismo. 


\section{REFERÊNCIAS}

ADORNO, Sérgio. Os aprendizes do poder: o bacharelismo liberal na política brasileira. Rio de Janeiro: Paz e Terra, 1988.

BASTOS, Aurélio Wander. O ensino jurídico no Brasil. 2. ed. Rio de Janeiro: Lumen Juris, 2000 .

BENTO, Flávio; SANCHES, Samyra Haydêe Dal Farra Naspolini. A história do ensino do direito no brasil e os avanços da portaria 1886 de 1994. In: XVIII Congresso Nacional CONPEDI, 2009, São Paulo. Anais do XVIII Congresso Nacional do CONPEDI. Florianópolis: Fundação Boiteux, 2009. v. 1, p. 6186- 6211.

BOVE, Luiz Antônio. Uma visão histórica do ensino jurídico no brasil. In: Revista do Curso de Direito. São Paulo, v. 3, n. 3, p. 115-138, 2006.

BRASIL. Decreto n. 1.232-H, de 2 de janeiro de 1891, que aprova o regulamento das Instituições de Ensino Jurídico, dependentes do Ministério da Instrução Pública. In: Decretos do Governo Provisorio da Republica dos Estados Unidos do Brazil. Primeiro fascículo de 1 a 31 de janeiro de 1891. Rio de Janeiro: Imprensa Nacional, 1891. Disponível em: <http://www.camara.gov.br/Internet/InfDoc/novoconteudo/Legislacao/Republica/LeisOceriza das/1891dgp-jan.pdf>, p. 5-67. Acesso em 16 jun. 2015.

BRASIL. Decreto n. 3.903, de 12 de janeiro de 1901, que aprova o regulamento das Faculdades de Direito. Disponível em: <http://legis.senado.gov.br/legislacao/ListaTexto Integral. action?id=44848\&norma=60599>. Acesso em 20 jul. 2015.

BRASIL. Decreto $n^{\circ} 8.659$, de 5 de Abril de 1911, que aprova a Lei Orgânica do Ensino Superior e do Fundamental na República. Disponível em: <http://www2.camara.leg.br/legin/ fed/decret/1910-1919/decreto-8659-5-abril-1911-517247-republicacao-101878-pe.html>.

Acesso em 20 jul. 2015.

BRASIL. Lei $n^{\circ} 314$, de 30 de outubro de 1895, que reorganiza o ensino das Faculdades de Direito. Disponível em: <http://www2.camara.leg.br/legin/fed/lei/1824-1899/lei-314-30outubro-1895-540752-publicacaooriginal-41651-pl.html>. Acesso em 23 jul. 2015

CORDEIRO NETO, Holmes; AMORIM, Rosendo Freitas de. O ensino superior na primeira república no Brasil e a pedagogia de Ruy Barbosa. In: XXIII Congresso Nacional do CONPEDI, 2014, João Pessoa. Direito, ensino e metodologia jurídicos II. XXIII Congresso Nacional do CONPEDI. Florianópolis: CONPEDI, 2014, p. 510-535.

GALDINO, Flávio Antonio Esteves. A Ordem dos Advogados do Brasil na reforma do ensino jurídico. In: Ensino Jurídico OAB: 170 anos de cursos jurídicos no Brasil. Brasília: OAB, Conselho Federal, 1997, p. 155-186.

LOPES, José Reinaldo de Lima. O direito na história: lições introdutórias. 3. ed. São Paulo: Atlas, 2011. 
MACHADO, Antônio Alberto. Ensino jurídico e mudança social. 2. ed. São Paulo: Expressão Popular, 2009.

MARTINEZ, Sérgio Rodrigo. A evolução do ensino jurídico no Brasil. Revista Jus Navigandi, Teresina, ano 11, n. 969, 26 fev. 2006. Disponível em: <http://jus.com.br/artigos/ 8020/a-evolucao-do-ensino-juridico-no-brasil\#ixzz3gedUPfAe>. Acesso em 13 jun. 2015.

MESQUITA, Marcelo Rocha. O perfil ideal do graduando em direito: sugestões para a sua obtenção. In: XXIII Congresso Nacional do CONPEDI, 2014, João Pessoa. Direito, ensino e metodologia jurídicos I. XXIII Congresso Nacional do CONPEDI. Florianópolis: CONPEDI, 2014. p. 394-413.

OLIVEIRA, José Sebastião de; TOFFOLI, Vitor. O ensino jurídico em nosso país no período imperial e no primeiro momento republicano, sua evolução histórico-metodológica e suas consequências na contemporaneidade. Sistema Jurídico e Direitos fundamentais individuais e Coletivos. 1. ed. Florianópolis: Fundação Bouitex, 2012, p. 8648-8675.

SUPREMO TRIBUNAL FEDERAL. Carlos Maximiliano Pereira dos Santos. Disponível em: <http://www.stf.jus.br/portal/ministro/verMinistro.asp?periodo=stf\&id=230>. Acesso em 20 jul. 2015.

VENANCIO FILHO, Alberto. Análise histórica do ensino jurídico no Brasil. In: Encontros da UnB: Ensino Jurídico. Brasília: Editora Universidade de Brasília, 1978-1979.

Das Arcadas ao Bacharelismo: 150 anos de Ensino Jurídico no Brasil. São Paulo: Perspectiva, 1982. 